\title{
Wake Turbulence Structure Downstream of a Cambered Airfoil in Transonic Flow: Effects of Surface Roughness and Freestream Turbulence Intensity
}

\author{
Qiang Zhang and Phillip M. Ligrani \\ Turbomachinery Laboratory, Department of Engineering Science, University of Oxford, Parks Road, Oxford OX1 3PG, UK
}

Received 3 April 2006; Revised 18 July 2006; Accepted 20 July 2006

The wake turbulence structure of a cambered airfoil is studied experimentally, including the effects of surface roughness, at different freestream turbulence levels in a transonic flow. As the level of surface roughness increases, all wake profile quantities broaden significantly and nondimensional vortex shedding frequencies decrease. Freestream turbulence has little effect on the wake velocity profiles, turbulence structure, and vortex shedding frequency, especially downstream of airfoils with rough surfaces. Compared with data from a symmetric airfoil, wake profiles produced by the cambered airfoils also have significant dependence on surface roughness, but are less sensitive to variations of freestream turbulence intensity. The cambered airfoil also produces larger streamwise velocity deficits, and broader wakes compared to the symmetric airfoil.

Copyright (C) 2006 Q. Zhang and P. M. Ligrani. This is an open access article distributed under the Creative Commons Attribution License, which permits unrestricted use, distribution, and reproduction in any medium, provided the original work is properly cited.

\section{INTRODUCTION}

The wake flow characteristics behind smooth, two-dimensional bluff bodies have been experimentally studied by many researchers. Valuable information on the unsteady flow field, including the mechanics of vortex formation, vortex shedding frequency, velocity, vorticity, turbulence-energy production, is provided by investigations by Gerrard [1], Perry et al. [2], Cantwell and Coles [3], Makita and Sassa [4], Cimbala and Krein [5], Zhou and Antonia [6], and Ong and Wallace [7]. A comprehensive review of these research works is given by Zhang et al. [8], who investigate the effects of surface roughness on the wake turbulence structure of symmetric turbine airfoils with different freestream turbulence intensity levels in a high speed subsonic flow. According to these authors, nondimensional vortex shedding frequencies decrease as either the level of surface roughness or the turbulence intensity increases.

Of the few other investigations of wake turbulence structure produced by airfoils and turbine blades, the experiments of Cambell [9] provide information on the nature of wake turbulence downstream of a two-dimensional airfoil at low speeds, including turbulence intensity distributions and power spectra of the velocity fluctuations. An experimental investigation of the near wake produced by a thin airfoil is reported by Hah and Lakshminarayana [10]. Distributions of mean velocity, turbulence intensity, and Reynolds stress components illustrate the complex nature of the near wake. Han and Cox [11] detect von Kármán vortices near the trailing edge region of a turbine airfoil, and conclude that von Kármán vortex spacing in the near-wake region increases with distance from the trailing edge, partly because of reduced velocity deficits. Sieverding and Heinemann [12] examine vortex shedding and development both from flat plates and turbine cascades in an effort to correlate Strouhal numbers with Mach number and Reynolds number, and to relate vortex shedding frequencies to the boundary layer character on the blade surfaces. Sieverding et al. [13] report another study of the wakes behind turbine blades, which involves combined experimental and numerical efforts. Considered are the effects of boundary layer thickness and boundary layer state on time-averaged normal Reynolds stresses surveys, unsteady wake characteristics, vortex formation length, and time-varying wake density distributions. Another recent work by Sieverding et al. [14] provides additional information on unsteady wake characteristics behind turbine blades. Zhang and Ligrani [15] describe Mach number and surface roughness effects on the aerodynamic performance of a symmetric airfoil, including measurements of 
local wake velocity profiles at different experimental conditions.

In contrast to the investigations of Zhang et al. [8] and Zhang and Ligrani [15], in which a symmetric airfoil is employed, the present study employs a cambered turbine airfoil, which produces substantial flow turning and matches an airfoil configuration employed in an industrial application. Considered are the influences of surface roughness and freestream turbulence intensity. The effects of airfoil camber and streamline curvature are also illustrated by comparing data measured downstream of the symmetric and cambered airfoils. These comparisons are useful and important because they illustrate the effects of airfoil camber and airfoil design in producing different trailing edge separation phenomena and different wake deficit behavior. In the present study, three different freestream turbulence intensity levels are employed in a transonic flow. One smooth cambered airfoil is employed, along with two other airfoils with threedimensional roughness distributed uniformly over the entire airfoil surfaces. A fourth airfoil is also employed with roughness of different sizes distributed over the airfoil surface (i.e., a variable rough surface). All four turbine airfoils have the same shape and exterior dimensions. As such, the present study presents new information on the combined effects of roughness and mainstream turbulence levels on the wakes which form downstream of cambered airfoils.

\section{EXPERIMENTAL APPARATUS AND PROCEDURES}

\subsection{Test section and flow characteristics}

The University of Utah Transonic Wind Tunnel (TWT) is used for the study. Detailed descriptions of this blow-downtype facility are provided by Jackson et al. [16] and Furukawa and Ligrani [17].

A schematic diagram of the test section with the cambered airfoil is shown in Figure 1, including the wake coordinate system, where $x$ is the coordinate in the streamwise direction, and $y$ is the coordinate normal to this direction, where both are measured from the airfoil trailing edge. The inlet of the test section is $12.70 \mathrm{~cm}$ by $12.70 \mathrm{~cm}$. The side and bottom walls of the test section are made of steel, and top wall is made up of acrylic. Appropriate cascade flow conditions are maintained, in part, by a pair of adjustable bleed ducts which are located on the two-side walls near the downstream portion of the inlet duct, as shown in Figure 1. The flow rate of each bleed duct is regulated using an adjustable ball valve. Following these bleed ducts, the test section walls have the same pressure side and suction side contours as the test airfoil. The exit area and exit flow direction from the cascade test section can be altered by changing the angles of the two exit tailboards, which are also shown in Figure 1. Thus, (i) changing the total pressure at the test section inlet using the pressure regulator/sliding gate valve arrangement, (ii) changing the angular positions of the two tailboards, and (iii) adjusting the ball valves of the bleeding system are employed to alter the Mach number distribution along the airfoil. When
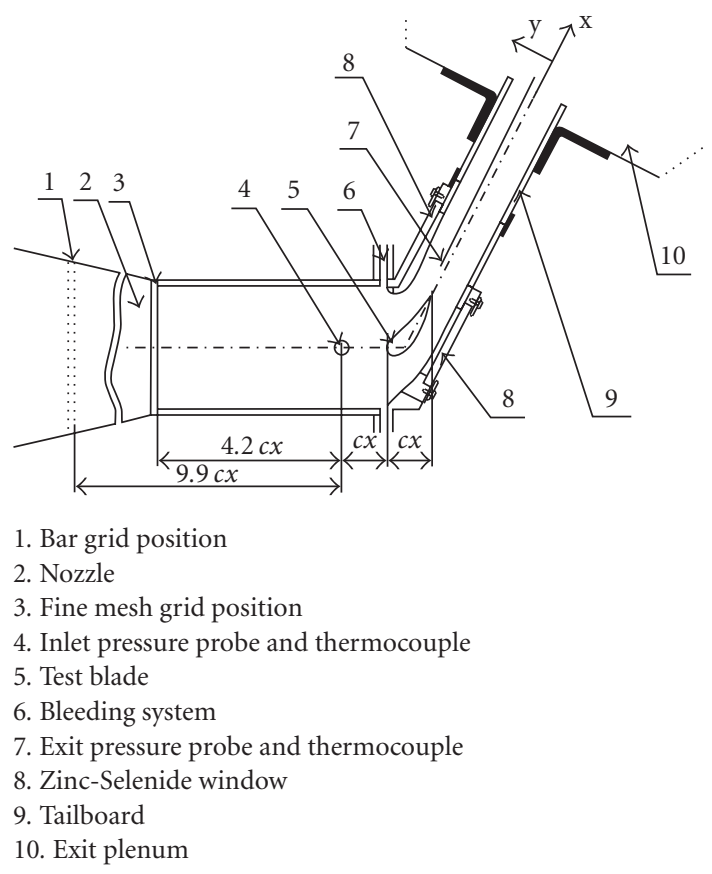

Figure 1: Schematic diagram of the test section.

the airfoil Mach number distribution matches the industrial distribution (which is discussed later in the paper), the static pressure field and the velocity distribution are scaled to also match this industrial application, which means that the flow field around the airfoil is representative of periodic cascade flow.

Three different arrangements are used at the inlet of the test section to produce three different levels of mainstream turbulence intensity: (i) no grid or bars, (ii) fine mesh grid, and (iii) cross bars. The locations of the last two of these are shown in Figure 1. The fine mesh grid consists of an array of 4 square rods arranged horizontally and 4 square rods arranged vertically. Each rod is spaced $25.4 \mathrm{~mm}$ from adjacent rods, and is $6.5 \mathrm{~mm}$ on each side. The open area amounts to 48 percent of the inlet area. The cross-bars device consists of two parallel bars, where each is $25.4 \mathrm{~mm}$ in width, with $25.4 \mathrm{~mm}$ spacing from the adjacent bar, and $25.4 \mathrm{~mm}$ spacing from the top and bottom walls of the inlet duct. The open area amounts to 60 percent of the inlet area.

During each test, the inlet total pressure at the inlet of the test section is kept constant at $106 \mathrm{kPa}$. Corresponding exit freestream Mach number, measured one axial chord length downstream of the airfoil trailing edge, is about 0.65 , and chord Reynolds number (based on exit flow conditions) is $0.9 \times 10^{6}$. Table 1 gives operating conditions employed in this study. Three different magnitudes of the inlet longitudinal turbulence intensity are also tabulated in Table 1. Here, turbulence intensity $\mathrm{Tu}$ is measured one axial chord length upstream of the airfoil leading edge, and is defined as the ratio of the root mean square of the longitudinal fluctuation velocity component divided by the local streamwise mean 
TABLE 1: Experimental operating conditions.

\begin{tabular}{l|lll}
\hline Exit Mach number & 0.65 & - & - \\
Exit Reynolds number* & $0.9 \times 10^{6}$ & - & - \\
Inlet Reynolds number* & $0.4 \times 10^{6}$ & - & - \\
Inlet Mach number & 0.23 & - & - \\
Inlet total pressure $(\mathrm{kPa})$ & 106 & - & - \\
Inlet turbulence intensity & $1.1 \%$ & $5.4 \%$ & $7.7 \%$ \\
Inlet turbulence length scale $(\mathrm{mm})$ & - & 2.7 & 4.7 \\
Inlet relative humidity & $15 \sim 20 \%$ & - & - \\
\hline
\end{tabular}

$*$ based on true chord length.

component of velocity. The longitudinal integral length scales are also given in Table 1 for $\mathrm{Tu}=5.4 \%$ and $\mathrm{Tu}=7.7 \%$.

To check the stability of the wakes produced by the bar grid and the fine mesh grid, spectra of longitudinal velocity fluctuations are measured one axial chord length upstream of the airfoil leading edge. These spectra show that peaks due to shed vortical events from the fine mesh grid are not present. A very low shedding frequency (around $100 \mathrm{~Hz}$ ) is produced by the bar grid, which is mostly due to the bar grid shape.

Inlet uniformity measurements are conducted at five different pitchwise locations at the inlet of the test section. With no turbulence grid employed, the total pressure and static pressure show excellent spatial uniformity at this location, varying by less than 0.5 percent of mean values. With the fine mesh grid and bar grid, the total pressure and static pressure generally vary less than 0.6 percent of mean values. The measurement location for these values is one axial chord length upstream of the airfoil leading edge. Note that the bar grid is installed further away from the leading edge of the airfoil compared to the position of the fine mesh grid, as shown in Figure 1. This maintains acceptable levels of uniformity in the flow as it approaches the airfoil.

\subsection{Test airfoils and surface roughness}

Table 2 gives geometric parameters of the cambered test airfoils. Four different airfoils, all with the same exterior dimensions but with different surface roughness characteristics, are used. One airfoil has a smooth surface, two other airfoils have uniform rough surfaces on both suction and pressure sides, and one airfoil has variable roughness on the pressure side. The roughness applied simulates the actual roughness which develops on operating turbine airfoils, over long operating times, due to particulate deposition and to spallation of thermal barrier coatings (TBCs). The roughness is applied by bonding nickel particles, manufactured by Praxair Surface Technologies Inc., to the airfoil surfaces. The approach employed to accomplish this is described by Zhang et al. [8]. The epoxy and the roughness particles are applied to an indented region located across the central span of the airfoil, which means that the mean level of the roughness is at the same level as the surrounding smooth surface. With this technique, the exterior dimensions of the surfaces of all four test airfoils
TABLE 2: Test airfoil geometric parameters.

\begin{tabular}{l|c}
\hline True chord $c$ & $7.27 \mathrm{~cm}$ \\
Axial chord $c x$ & $4.85 \mathrm{~cm}$ \\
Pitch $p$ & $6.35 \mathrm{~cm}$ \\
Span & $12.7 \mathrm{~cm}$ \\
Flow turning angle & $62.75^{\circ}$ \\
\hline
\end{tabular}

Note: dimensional magnitude of trailing edge thickness is proprietary and cannot be provided in the paper.

are the same, regardless of whether their surfaces are smooth or rough.

A schematic diagram of test turbine airfoil with rough surfaces is shown in Figure 2(a). Roughness elements are uniformly distributed along the airfoil surface. The airfoil with the uniform smaller-sized roughness elements has Praxair T1166F particles, which range in size from $20 \mu \mathrm{m}$ to $53 \mu \mathrm{m}$. The airfoil with the uniform larger-sized roughness elements has Praxair NI-914 particles, which range in size from $40 \mu \mathrm{m}$ to $200 \mu \mathrm{m}$. The airfoil with variable roughness is shown in Figure 2(b). Four types of different nickel-based powders are used on the pressure side of a test airfoil, while the suction side is smooth. Detailed information regarding the nickel powders and surface coverage for the variable rough airfoil is given in Table 3. The arrangement of variable rough surface is based on observations of roughened turbine airfoils from industrial applications. From these observations, the suction side is more or less uniform in roughness, and remains at or very close to the "as-cast" condition, even after very long operating times. Pressure side roughness, on the other hand, is more variable. Local roughness magnitudes are often the same as that on the suction side near the pressure side leading edge. Local roughness sizes then vary linearly to the full roughness size, which are typically reached at about $40 \%$ of the distance along the pressure surface.

The magnitudes of equivalent sand grain roughness $k s$ are determined for all surfaces tested using procedures which are described by van Rij et al. [18], Zhang et al. [8], and Zhang and Ligrani [15]. Magnitudes of equivalent sand grain roughness size for the three-dimensional, irregular roughness of the present study are given in Table 4, where each value is based on an average of 8 three-dimensional optical profilometry scans.

\subsection{Experimental procedures and instrumentation}

During each blow-down test, the total pressure, Reynolds number, and turbulence level at the test section inlet are maintained in a continuous and steady fashion for 45-second long time intervals. Such characteristics are not only due to the TWT design, but also due to the excellent performance characteristics of the TWT mainstream air pressure regulator and its controller.

Hot-wire anemometry is used for the measurement of wake turbulence quantities. A single horizontal-type platinum-plated tungsten hot-wire sensor, with a diameter of 


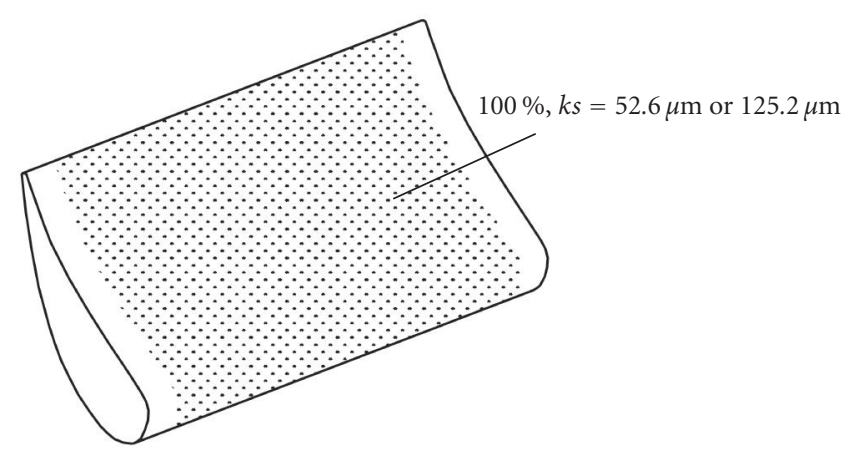

(a)

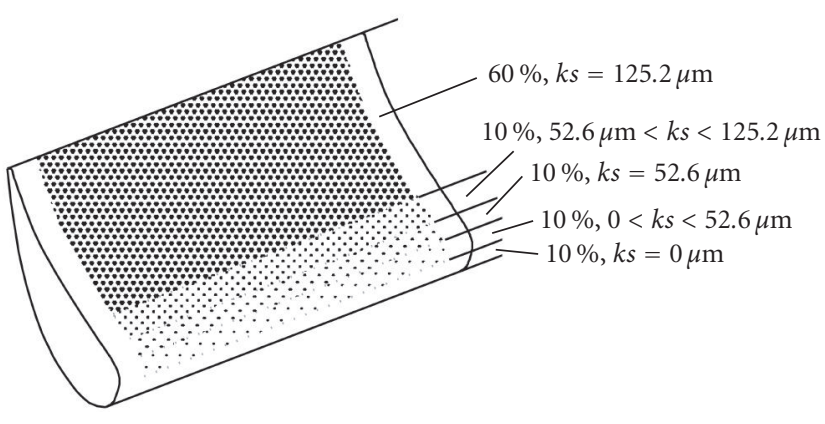

(b)

FIgURE 2: Test airfoils with rough surfaces. (a) Airfoil with uniform roughness. (b) Airfoil with variable roughness on the pressure side.

TABLE 3: Nickel-based powders used on the test airfoil with variable surface roughness on the pressure side.

\begin{tabular}{l|cc}
\hline Percentage of the surface distance & Powder & Size \\
\hline $0-10 \%$ & - & 0 \\
$10 \%-20 \%$ & NI-105 & $5-45$ \\
$20 \%-30 \%$ & T1166F & $20-53$ \\
$30 \%-40 \%$ & NI-107 & $45-106$ \\
$40 \%-100 \%$ & NI-914 & $40-200$ \\
\hline
\end{tabular}

TABLE 4: Characteristics of rough surfaces investigated.

\begin{tabular}{|c|c|c|c|}
\hline Surface & $k(\mu \mathrm{m})$ & $k s(\mu \mathrm{m})$ & $k s / c x$ \\
\hline Smooth surface & 3.5 & .0094 & 0 \\
\hline $\begin{array}{l}\text { Rough surface with } \\
\text { nickel powder T1166F }\end{array}$ & 27.92 & 52.59 & .00108 \\
\hline $\begin{array}{l}\text { Rough surface with } \\
\text { nickel powder NI-914 }\end{array}$ & 64.03 & 125.19 & .00258 \\
\hline Variable rough surface* & $3.5-64.03$ & $.0094-125.19$ & $0-.00258$ \\
\hline
\end{tabular}

* See Figure 3 and Table 3.

$12.7 \mu \mathrm{m}$ and a length of $2.54 \mathrm{~mm}$, is employed to measure the time varying longitudinal component of velocity. The hotwire sensor is located one axial chord length downstream of the airfoil. In situ calibration is achieved by mounting a fourhole conical-tipped pressure probe with an attached copperconstantan thermocouple at a location immediately adjacent to the hot-wire sensor. Mach numbers, sonic velocities, total temperatures, and static temperatures are determined from measured values of total pressure, static pressure, and recovery temperature. As tests are conducted, the hot-wire sensor is traversed across the wake region using a two-axis traversing sled with two Superior Electric M092-FF-206 synchronous stepper motors, connected to a Superior Electric Model SS2000I programmable motion controller and a Superior Electric Model SS2000D6 driver. Commands for the operation of the motion controller are provided by LABVIEW 7.0 software and pass though a serial port after they originate in a Dell Precision 530 PC workstation.
The hot-wire probe is driven by a Disa $55 \mathrm{M} 10$ constanttemperature hot-wire anemometer bridge. The analog signal from this bridge is then processed using a Dantec 56N20 signal conditioner with a low-pass, antialiasing filter set to $100 \mathrm{kHz}$, which is also the maximum detectable frequency. The time-varying output voltage signal is then sampled at a $200 \mathrm{kHz}$ rate using a DATEL PCI441D I/O board installed in the Dell Precision 530 PC workstation. Note that the most important spectral results from the present investigation are generally obtained at frequencies well below $70 \mathrm{kHz}$, and as such, are unaffected by any alterations due to lowpass filter behavior or by hot-wire system frequency response limitations at higher frequencies. At each measurement location, 400000 voltage values are sampled over a two-second period. Data are acquired using LABVIEW 7.0 software and then processed further using Matlab 6.1 software. The determination of the turbulence length scale is accomplished by integrating the autocorrelation functions which are deduced from the time-varying longitudinal velocity signals, as mentioned. Power spectral density profiles of streamwise velocity fluctuations $\left(u^{\prime}\right)$ are obtained using $4096\left(2^{12}\right)$ points of fast Fourier transforms (FFT). Each power spectral density profile is determined from an ensemble average of 10000 individual profiles obtained over overlapping time intervals which are spread over a total time period of 1.5 seconds.

\subsection{Estimated uncertainties of measured quantities}

Uncertainty estimates are based on 95 percent confidence levels and are determined using single sample uncertainty determination methods. The uncertainty of temperatures measured with thermocouples is $\pm 0.15^{\circ} \mathrm{C}$. Pressure uncertainty is $0.25 \mathrm{kPa}$. Chord Reynolds number uncertainty is about \pm 2.5 percent for a value of $0.95 \times 10^{6}$. The experimental uncertainty of the time-averaged magnitude of local streamwise velocity is \pm 2.5 percent. The estimated uncertainty of the time-averaged magnitude of the longitudinal Reynolds normal stress (or the mean square of the fluctuating velocity component) is about \pm 5.0 percent. This gives an uncertainty for the local turbulence intensity Tu of approximately \pm 3.3 percent. 


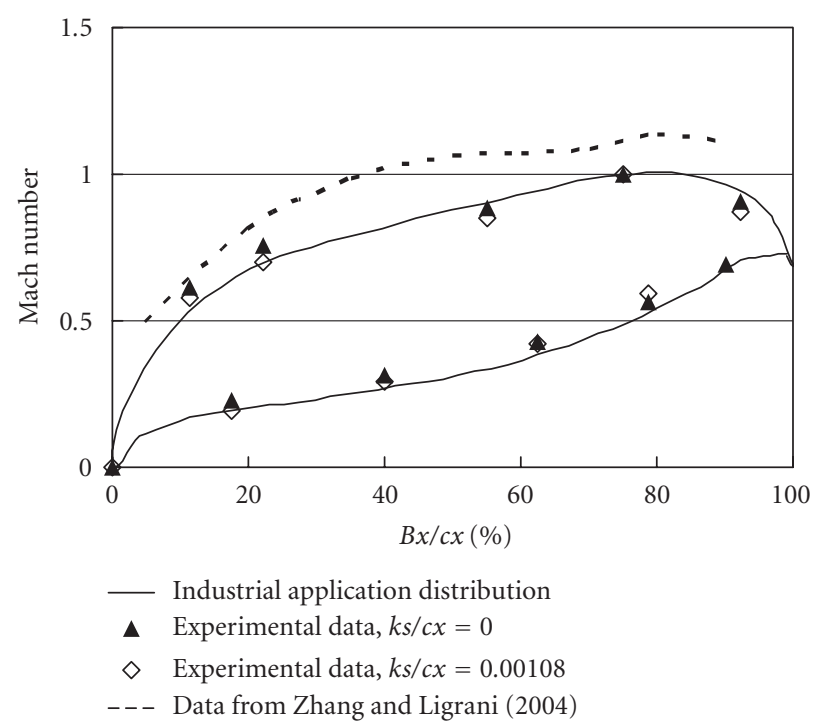

FIGURE 3: Mach number distributions along the cambered test airfoil.

\section{EXPERIMENTAL RESULTS AND DISCUSSION}

\subsection{Mach number distributions}

Figure 3 shows the Mach number distribution along the turbine airfoil pressure side and along the airfoil suction side for the present operating condition. The data shown in Figure 3 are based upon measurements of total pressure at the test section inlet and airfoil midspan static pressures. These are measured using two different airfoils which are constructed especially for this task: (i) a smooth airfoil $(k s / c x=0)$, and (ii) an airfoil with uniform small-sized roughness $(k s / c x=$ 0.00108). Each of these airfoils has five pressure taps on the pressure side, and five pressure taps on the suction side, as well as one pressure tap located on the leading edge at the airfoil midspan. Figure 3 shows that the Mach number distributions on pressure and suction sides are in excellent agreement with data obtained from an operating industrial engine. This Mach number distribution is transonic on the airfoil suction side and subsonic on the pressure side. Note that an adverse pressure gradient is present on the suction side for $B x / c x>0.90$. As a result, a diffusion flow field and possibly earlier flow separation are expected to occur near the suction side trailing edge. The acceleration present on the pressure side is expected to produce thinning of the turbulent boundary layers accompanied by a suppression of boundary layer turbulence.

Figure 3 also shows that the Mach number distributions for the roughened airfoil with $k s / c x=0.00108$ and the smooth airfoil are in excellent agreement with each other for the same cascade inlet flow experimental condition. This means that (i) the roughness has little effect on the airfoil Mach number and surface static pressure distributions, (ii) the contour shapes of the smooth airfoil and uniformly roughened airfoil with $k s / c x=0.00108$ are the same, and

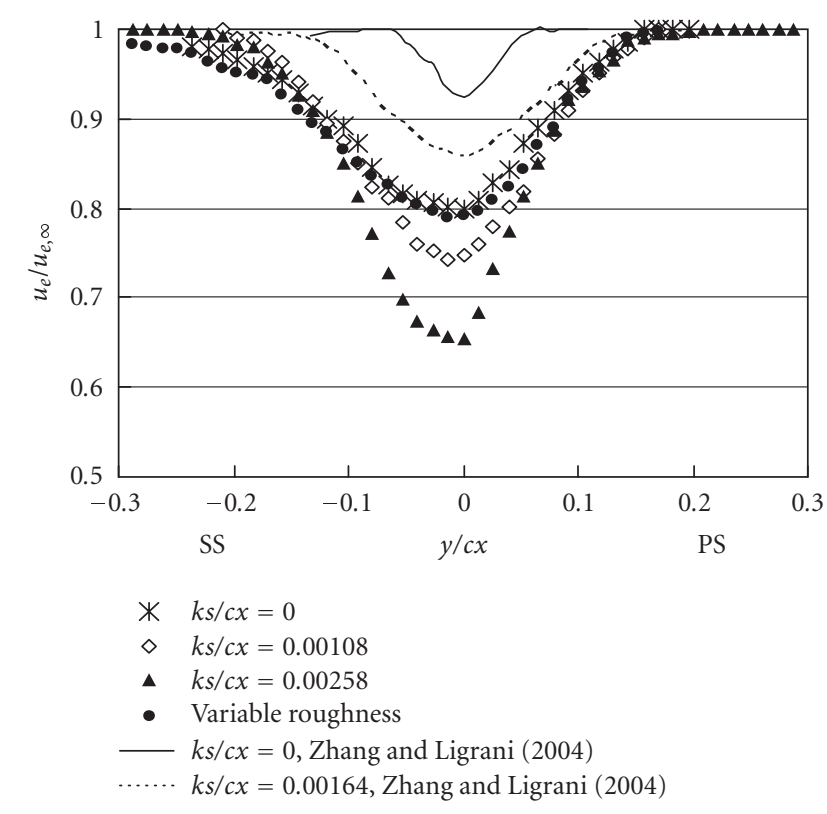

FIGURE 4: Normalized wake mean velocity distributions measured one axial chord length downstream of the cambered airfoils with different rough surfaces for $\mathrm{Tu}=1.1$ percent.

(iii) the flow field around the airfoil is representative of periodic cascade flow. Note that the trailing edge area is not accessible for measurement because static pressure tap tubes cannot be installed in the portion of the airfoil with such a small trailing edge diameter.

Also shown in Figure 3 is a Mach number distribution employed by Zhang and Ligrani [15], which is transonic on both sides of a symmetric airfoil. In their study, Mex $=0.9$, inlet $\mathrm{Re}=0.54 \times 10^{6}$, whereas Mex $=0.65$ and inlet $\mathrm{Re}=$ $0.4 \times 10^{6}$ for the present study. Their results provide evidence of similar suction side boundary layer development as the present study, except that magnitudes of their Mach number distribution are slightly higher, and the local adverse pressure gradient located near the suction surface trailing edge of the present cambered airfoil is not evident.

\subsection{Wake velocity profiles}

The effects of surface roughness and freestream turbulence on the local wake velocity profiles are illustrated by data presented in Figures 4 and 5.

Figure 4 shows normalized local mean velocity profiles measured one axial chord length downstream of the test airfoil trailing edge for $\mathrm{Tu}=1.1 \%$ (with no turbulence generator installed). Data from the present investigation are given for a smooth airfoil, an airfoil with uniform smallsized roughness $(k s / c x=0.00108)$, an airfoil with uniform large-sized roughness $(k s / c x=0.00258)$, and an airfoil with variable roughness. Figure 4 shows that mean velocity deficits increase at each $y / c x$ location within the wake as $k s / c x$ increases. Generally, broader wakes with increased roughness size are due to different boundary layer 
development and increased turbulent diffusion within the wake. The boundary layer changes resulting from increased magnitudes of surface roughness generally include earlier laminar-turbulent transition, augmented mixing and turbulent transport, more rapid boundary layer streamwise development, and thicker boundary layers at airfoil trailing edges.

The association of wake velocity deficits with the aerodynamic losses caused by smooth and the roughened airfoils is discussed by a number of investigations, such as Bammert and Sandstede [19, 20], Kind et al. [21], Bogard et al. [22], Abuaf et al. [23], and Leipold et al. [24]. More recently, Hummel et al. [25] and Boyle and Senyitko [26] have presented important wake total pressure loss data to provide information of the effects of surface roughness effect over a range of Reynolds numbers.

Also included in Figure 4 are normalized local mean velocity profiles for symmetric airfoils with smooth and rough surfaces $(k s / c x=0$ and $k s / c x=0.00164$, resp.) by Zhang and Ligrani [15]. Their operating conditions are described earlier, and the Mach number distribution along their airfoil is shown in Figure 3. Compared with the symmetric wake velocity profiles by Zhang and Ligrani [15], Figure 4 shows that the wake profiles from the present study are asymmetric, with much larger velocity deficits at each $y / c x$ location when compared at approximately the same value of $k s / c x$. This asymmetry is illustrated by suction side wakes (at negative $y / c x$ ) which are thicker than the pressure side wakes (at positive $y / c x$ ). This is mostly due to different growth and development of boundary layers on the suction and pressure sides of the cambered airfoil. On the suction side, where local freestream velocities are higher, the boundary layers develop until they are strongly diffused from the downstream portion of the vane at $B x / c x>0.90$, which gives a thicker wake immediately downstream of the trailing edge. On the pressure side, boundary layer thickness is usually much smaller than on the suction side because of continuous local flow acceleration. Figure 4 also shows that the differences between wake velocity deficits for the smooth and rough symmetric airfoils (with $k s / c x=0$ and $k s / c x=0.00164$, resp.) are larger on a percentage basis, compared with the alterations produced by the same change of surface roughness on the cambered airfoil. This means that wake velocity deficits produced by the symmetric airfoil are more sensitive to alterations of surface roughness magnitude.

Figure 4 also includes measurements made downstream of the airfoil with variable roughness shown in Figure 2(b). In most cases, the variable surface roughness profile gives slightly larger velocity deficits compared to the ones produced by the smooth airfoil. Thus, the variable roughness placed on the airfoil pressure side increases wake velocity deficits only by small amounts, compared with those produced by uniform roughness on both pressure and suction sides. This provides additional evidence that roughness on the airfoil pressure side has relatively smaller effects on the mean velocity profile within the wake (compared to roughness placed on the suction side). Figure 4 also shows that the suction side wake profile at $y / c x<0$ is widened somewhat for the airfoil with variable roughness, even though this airfoil has a smooth suction side. This is believed to be connected to different rates of boundary layer development (Bammert and Sandstede [20]) as different levels of roughness are encountered along the airfoil pressure surface, which give different magnitudes of boundary layer mixing and losses, and a different wake initial condition near the airfoil trailing edge, compared to airfoils with uniformly roughened surfaces.

Figures 5(a) and 5(b) present results which illustrate the effects of different inlet turbulence levels on normalized wake mean velocity profiles for the smooth airfoil with $k s / c x=0$, and for the airfoil with big-sized roughness and $k s / c x=$ 0.00258 , respectively. Results are given for Tu magnitudes of 1.1 percent, 5.4 percent, and 7.7 percent. From a comparison of Figures 5(a) and 5(b) with Figure 4, it is evident that the wake profiles are generally less sensitive to changes of the inlet turbulence intensity level than to changes of surface roughness. This is illustrated by normalized velocity profiles in Figures 5(a) and 5(b) for various inlet turbulence intensity levels which are generally similar. The only significant variation is slightly wider wakes and increased velocity deficits downstream of the cambered airfoil at $y / c x<-0.15$ which are tied to increases of freestream inlet turbulence intensity level from 1.1 percent to 7.7 percent. This is partially because boundary layers on suction surfaces are forced into transition earlier by higher freestream turbulence levels.

Data from the symmetric airfoil for a similar suction side Mach number distribution (shown in Figure 3 ) are also shown in Figures 5(a) and 5(b). Compared with the normalized velocity results from the cambered airfoil, results measured downstream of the symmetric airfoil show much smaller velocity deficits with slightly larger percentage variations from changing inlet turbulence intensity level. In this case, the symmetric wakes are broadened for $k s / c x=$ 0.00164 , with slightly smaller peak loss deficits for $k s / c x=0$ as mainstream turbulence intensity increases from 0.9 percent to 5.5 percent. These overall differences in behavior are mostly due to the streamwise curvature created by the cambered airfoil, and due to flow separation induced by the adverse pressure gradient present near the suction side trailing edge of the cambered airfoil, as discussed earlier (Figure 3).

\subsection{Turbulence intensity profiles}

Figures 6 and 7 present distributions of the local turbulence intensity $\mathrm{Tu}$ across the wake, which are measured in a plane located one axial chord length downstream of the airfoil trailing edge. The data in Figure 6 are given for four different cambered airfoils with different levels and types of surface roughness, where the inlet turbulence intensity level for each is 1.1 percent. Here, turbulence intensity levels increase significantly within the wake at each $y / c x$ value as $k s / c x$ increases. This is due to augmentations of mixing and turbulent transport in boundary layers which become thicker as the level of surface roughness on the airfoil increases. Note that, for each value of $k s / c x$, Tu values are roughly constant 


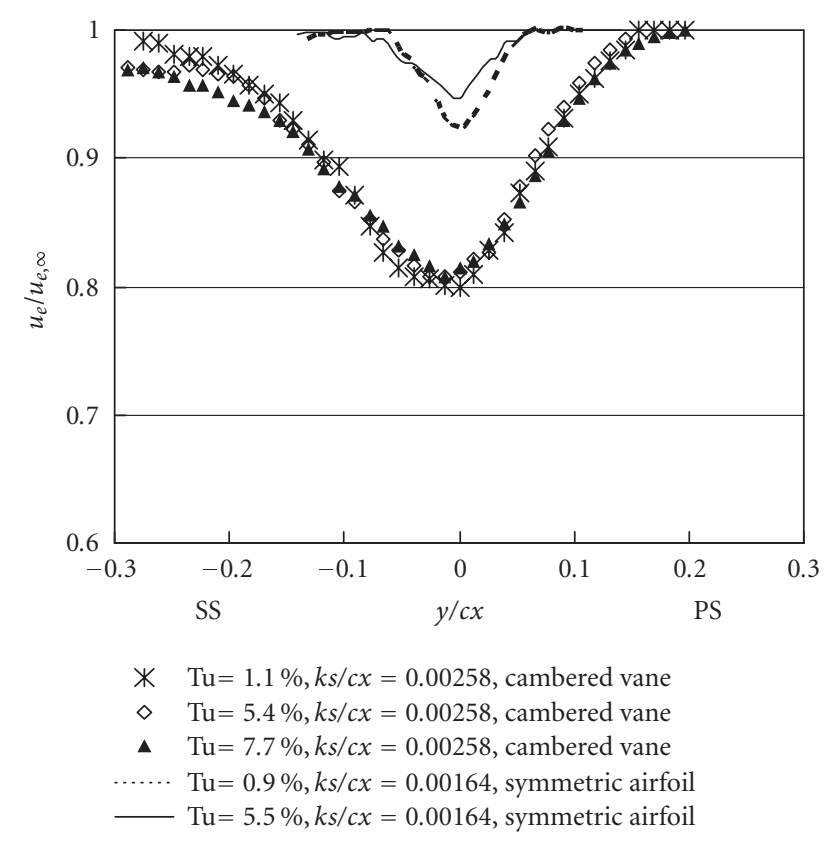

(a)

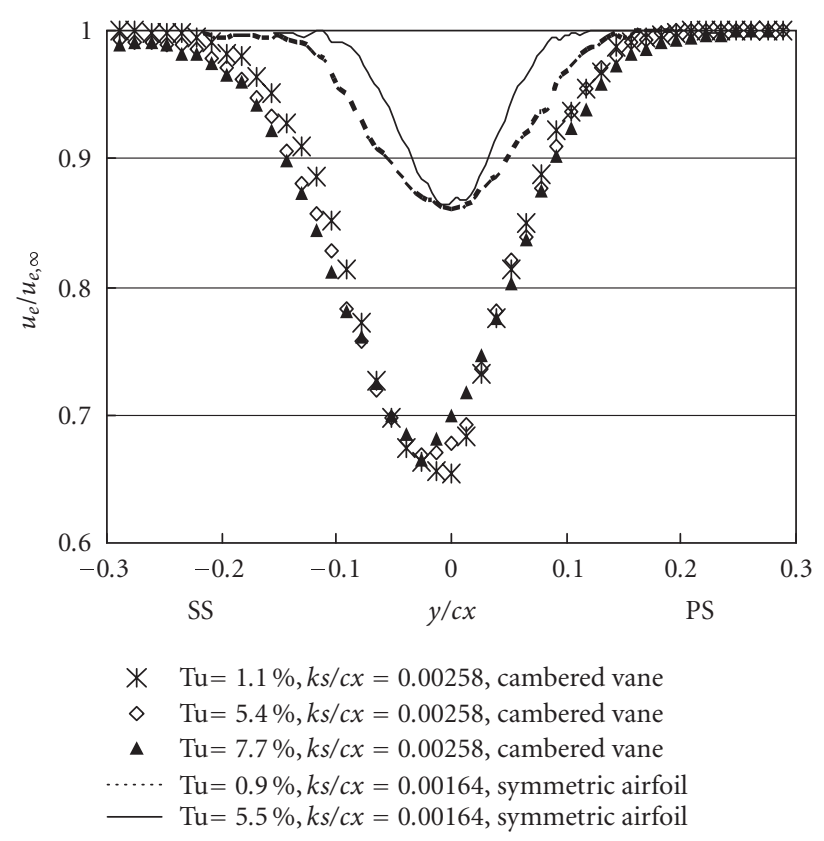

(b)

FIGURE 5: Normalized wake mean velocity distributions measured one axial chord length downstream of the cambered airfoils with different inlet turbulence intensity levels. (a) Smooth airfoil with $k s / c x=0$. (b) Airfoil with big-sized roughness, $k s / c x=0.00258$.

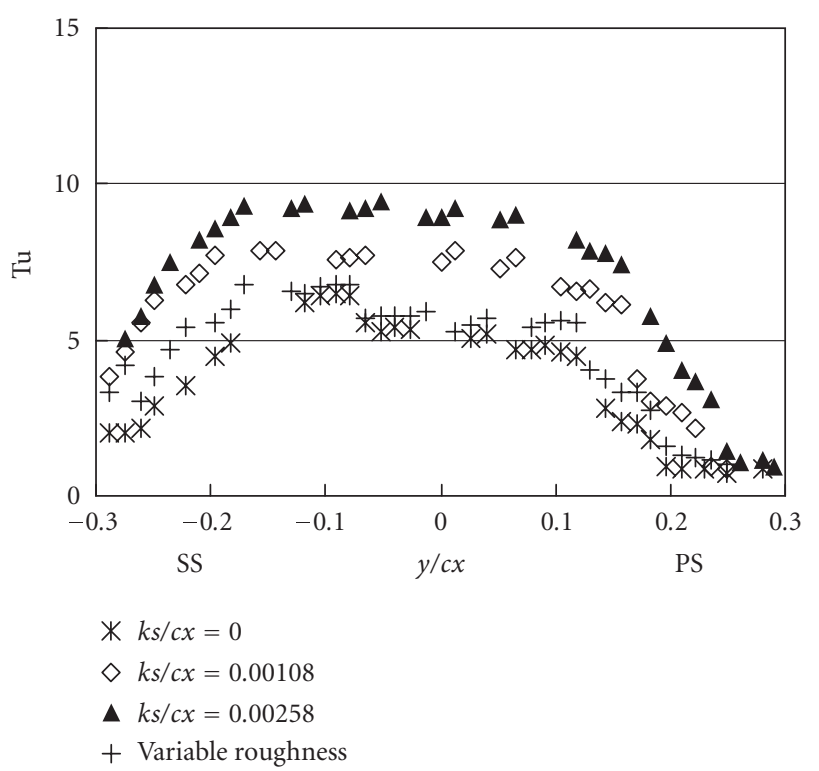

FIGURE 6: Profiles of turbulence intensity across the wakes measured one axial chord length downstream of the cambered airfoils with different rough surfaces for $\mathrm{Tu}=1.1$ percent.

as $y / c x$ varies within the wake region at $y / c x$ from -0.15 to +0.15 .

Figures 7(a) and 7(b) present wake turbulence intensity data at three different inlet turbulence intensity levels for the smooth airfoil with $k s / c x=0$, and for the airfoil with big-sized roughness with $k s / c x=0.00258$, respectively. Just like the normalized local velocity profiles shown in Figures 5(a) and 5(b), the Tu data in Figures 7(a) and 7(b) are quite similar at different inlet turbulence intensity levels. Slightly higher turbulence intensity magnitudes are present at $y / c x>$ 0.25 at higher inlet turbulence intensity levels. However, for most of the wake region, data differences for different inlet turbulence intensity levels are negligible and are within the experimental uncertainty. In a subsonic flow, Zhang et al. [8] present wake turbulence intensity profiles for a symmetric airfoil, as also shown in Figure 7(a). Magnitudes of their data are much lower than the cambered airfoil results, with values always lower than about 3 percent. In contrast to the present results, those data also provide evidence of slightly wider wake profiles at higher freestream turbulence intensity levels.

\subsection{Power spectral density (PSD) profiles}

The information on coherent structures in the wake, in the form of von Kármán vortices, is important for the numerical modeling of the trailing edge flow and for achieving correct blade loss predictions. Vortex shedding is also a nonnegligible excitation generator for acoustic resonances and structural vibrations, especially for bigger blades with decreasing stiffness. Here, power spectral density (PSD) profiles of the fluctuating longitudinal component of velocity are given in Figures 8-10.

Figures $8(\mathrm{a})$ and $8(\mathrm{~b})$ present PSD profiles measured at different locations within the wake at the same experimental condition. In this case, the wake is produced by a smooth airfoil with $\mathrm{Tu}=1.1$ percent. Spectra in Figures $8(\mathrm{a})$ and $8(\mathrm{~b})$ 

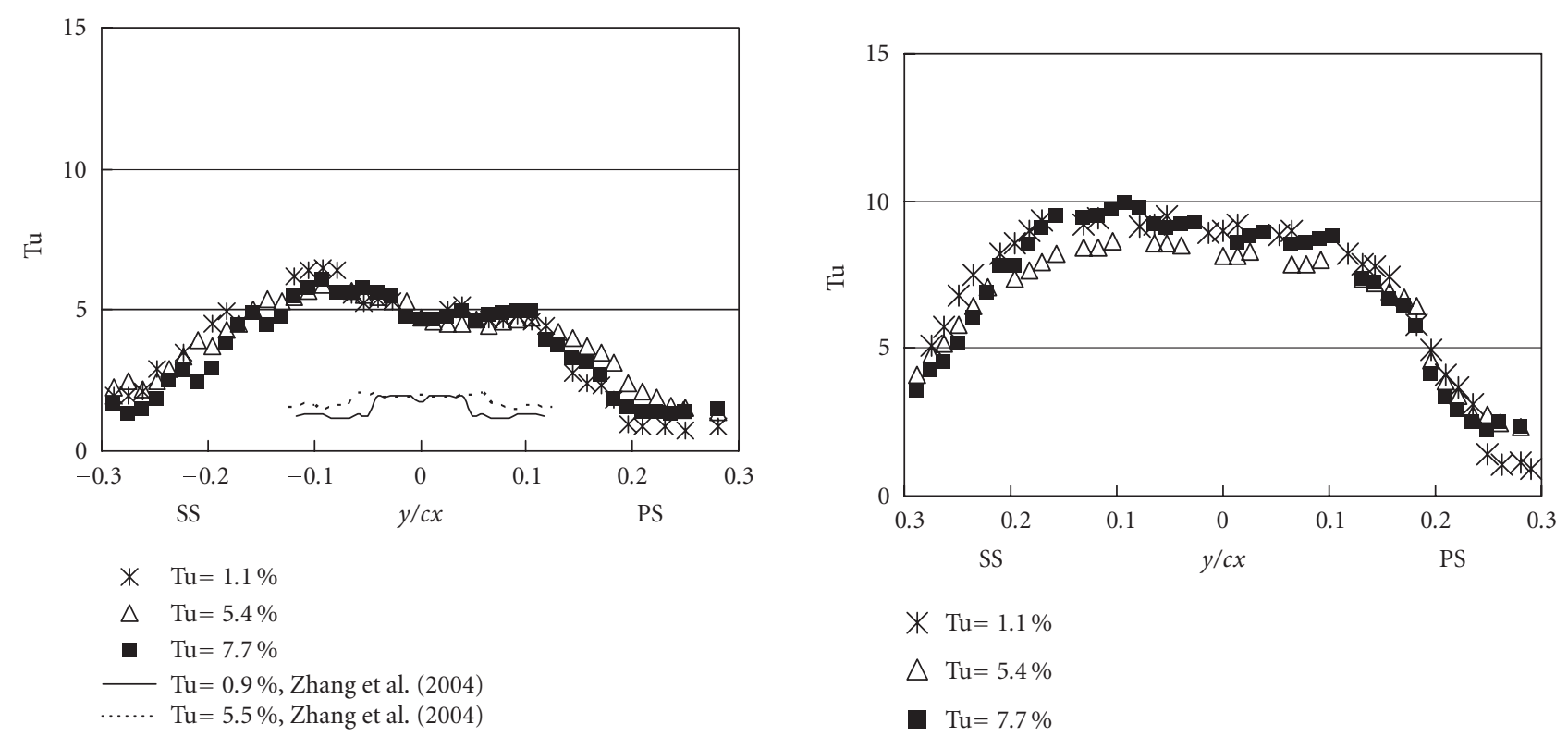

(a)

(b)

Figure 7: Profiles of turbulence intensity across the wakes measured one axial chord length downstream of the cambered airfoils with different inlet turbulence intensity levels. (a) Smooth airfoil, $k s / c x=0$. (b) Airfoil with big-sized roughness, $k s / c x=0.00258$.

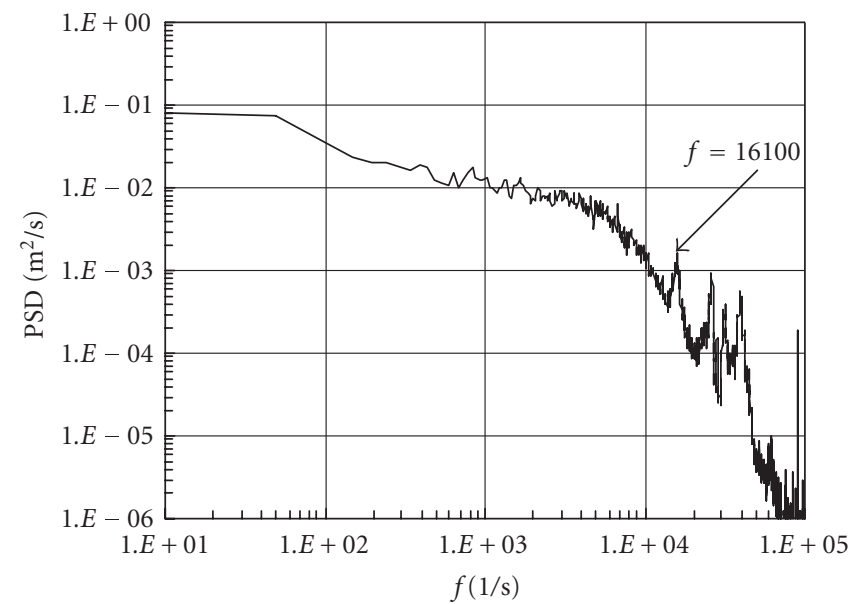

(a)

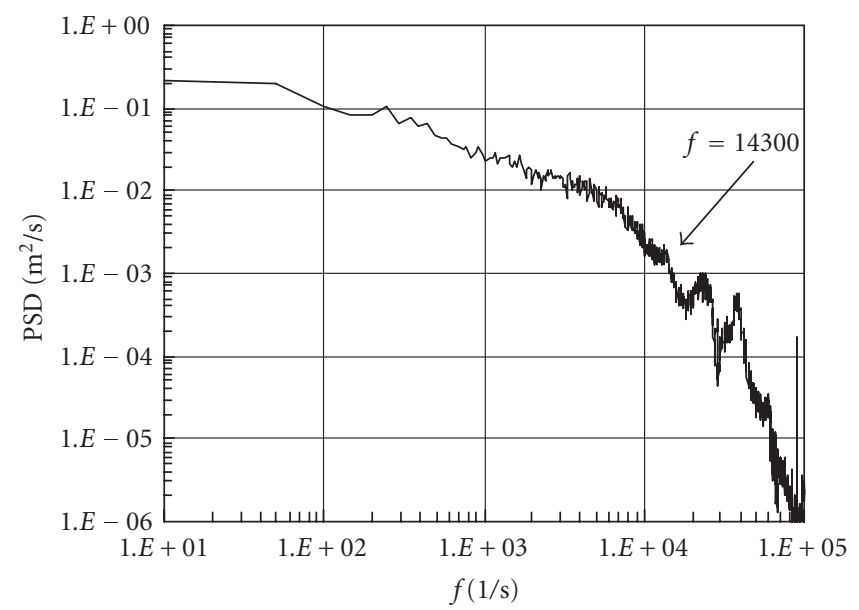

(b)

FIGURE 8: Power spectral density profiles measured in the wake flow one axial chord length downstream of the smooth cambered airfoil for $\mathrm{Tu}=0.9$ percent. (a) Pressure side wake at $y / c x=0.10$. (b) Suction side wake at $y / c x=-0.17$.

are given for the pressure side of the wake at $y / c x=+0.1$, and for the suction side of the wake at $y / c x=-0.17$, respectively. Several pronounced peaks in these PSD profiles represent higher energy at particular frequencies. The first peak with predominant energy and substantial strength in each PSD profile is generally identified as the primary vortex shedding frequency $f$. In Figure $8(a)$, this peak occurs at a frequency of $16100 \mathrm{~Hz}$, and in Figure 8(b), this peak occurs at a frequency of $14300 \mathrm{~Hz}$, however, compared with Figure 8(a), the first frequency peak in Figure 8(b) is not as clearly defined relative to background energy levels. These data thus show that the primary vortex shedding frequency is generally more easily identified in PSD profiles obtained within the pressure side wake. This is consistent with results from Han and Cox [11] and Sieverding et al. [14], who indicate that the pressure side vortex plays a more dominant role and is stronger than the suction side vortex. Some investigators believe that this is due to thinner pressure side boundary layers which often separate at or near the trailing edge. 


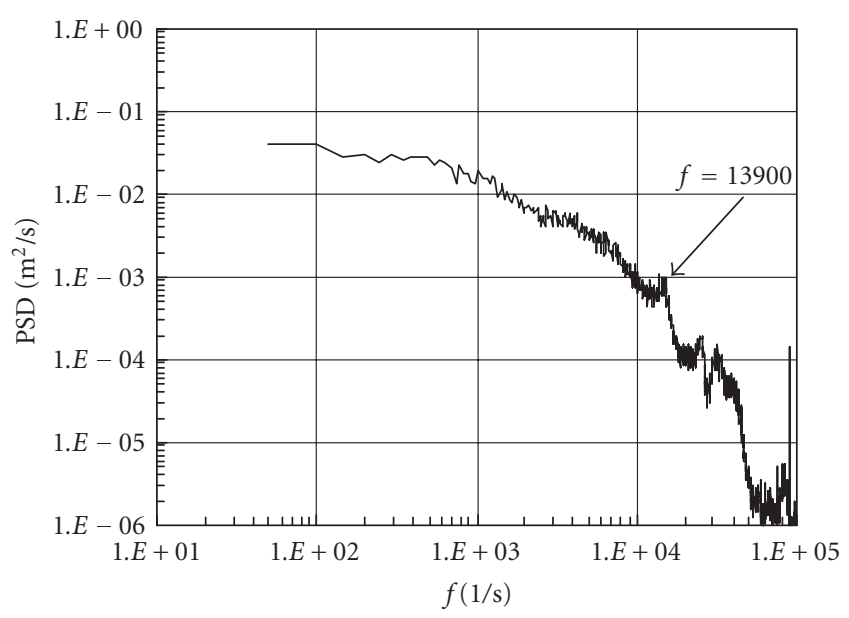

(a)

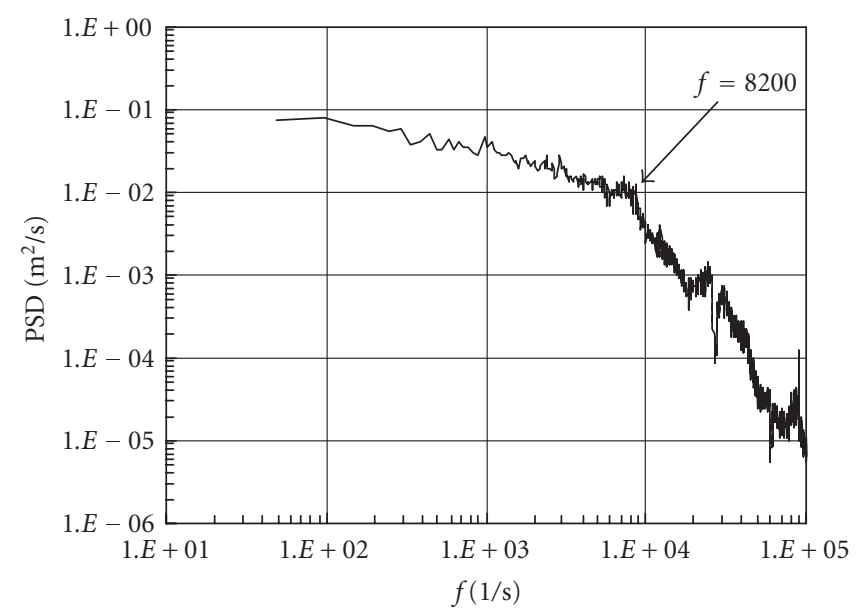

(c)

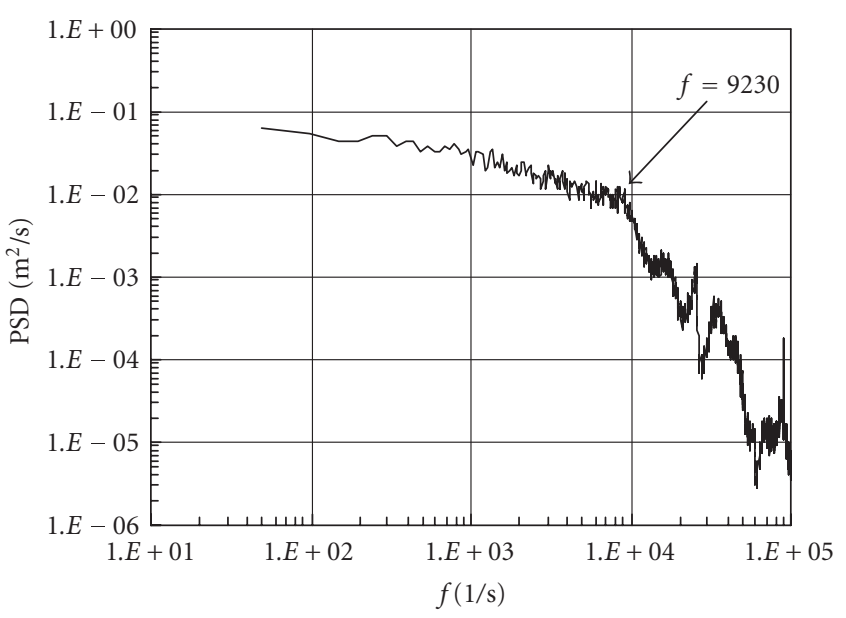

(b)

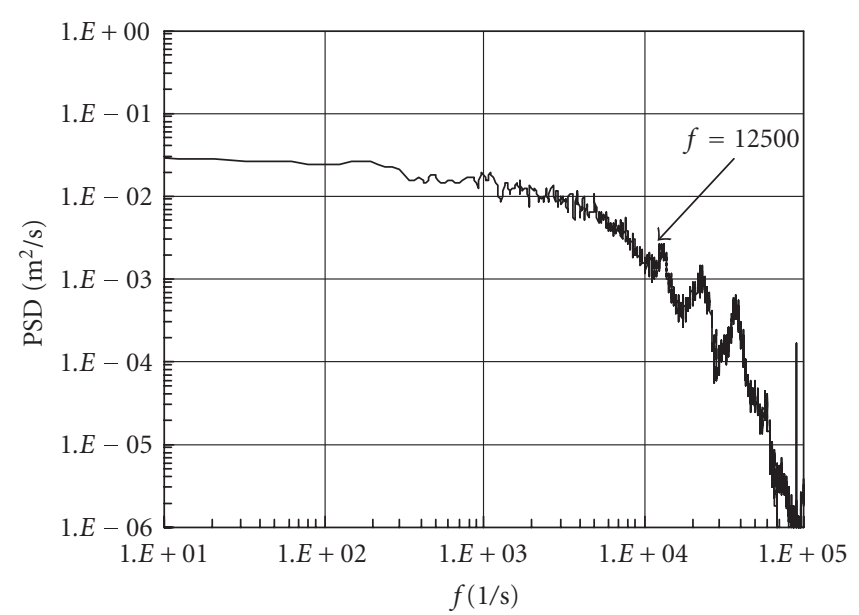

(d)

FIGURE 9: Power spectra density profiles measured in the pressure side wake at $y / c x=0.10$ one axial chord length downstream of the cambered airfoils for $\mathrm{Tu}=5.4$ percent. (a) Smooth airfoil, $k s / c x=0$. (b) Airfoil with small-sized roughness, $k s / c x=0.00108$. (c) Airfoil with big-sized roughness, $k s / c x=0.00258$. (d) Airfoil with variable roughness.

Figures 9(a)-9(d) show PSD profiles measured within the pressure sides of wakes at $y / c x \approx+0.1$, which are produced by airfoils with different rough surfaces with an inlet turbulence intensity of 5.4 percent. Figures 9(a), 9(b), and 9(c) show that increasing amounts of surface roughness decrease the frequency of vortex shedding $f$. The magnitude of vortex shedding frequency for the airfoil with variable roughness shown in Figure 9(d) lies between data for the smooth airfoil and the airfoil with uniform small-sized roughness. Similar characteristics are observed for other inlet turbulence intensity levels. As such, vortex shedding frequency variations with different levels of surface roughness are due to a number of factors. (i) First, boundary layers at airfoil trailing edges are thickened by larger surface roughness elements, which also increase boundary layer mixing and turbulence transport. These change the vortex dynamics in the wake because they provide the initial condition for the wake which develops downstream. (ii) Second, FLUENT numerical pre- diction results from the present study show that increased surface roughness causes slightly earlier separation near the present airfoil suction surface trailing edge. The resulting increased separation region gives larger vortices and greater dissipation of momentum in the wake. These then also cause the vortex shedding frequency to shift to lower values. (iii) As a result, diffusion within and from the wake is expected to be larger as airfoil surface roughness increases, and this also affects development of wake vortex shedding. Greater diffusion of momentum and vorticity in the wake also contributes to the reduction of vortex strength as surface roughness size increases.

A comparison of results in Figures 9(a) and 8(a) shows that the vortex shedding frequency for the smooth airfoil decreases slightly as the inlet turbulence intensity level increases. Augmented turbulence diffusion of vorticity between the surrounding freestream and the wake plays a role in producing this trend. According to Gerrard [1], this is because 


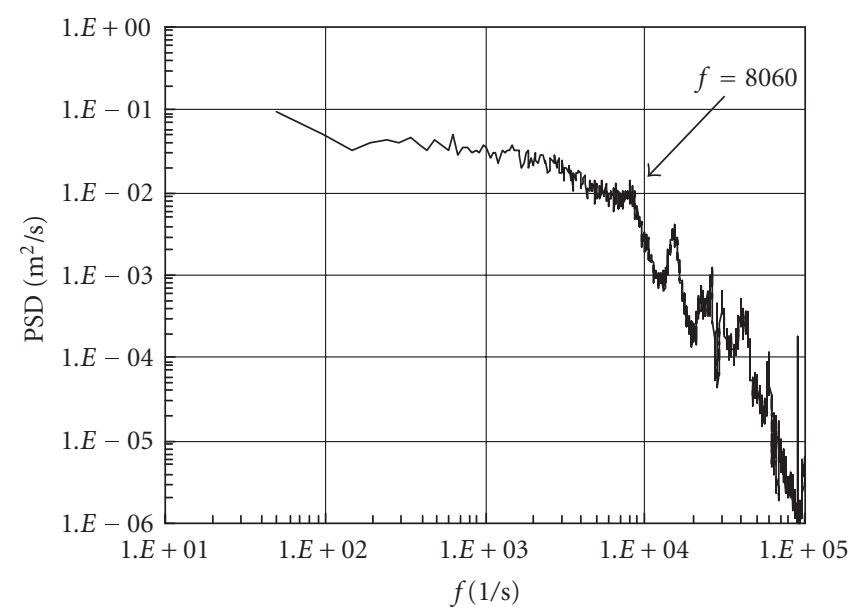

(a)

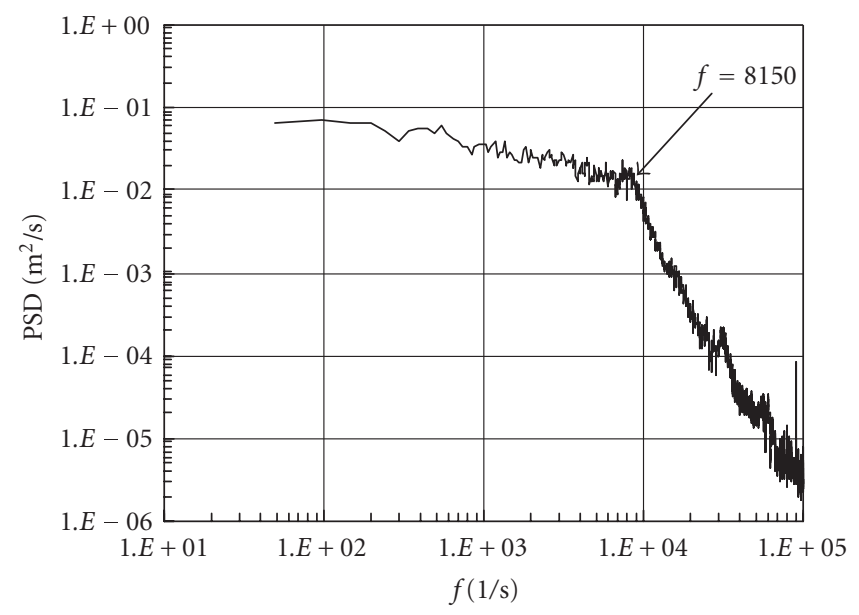

(b)

FIgUre 10: Power spectra density profiles measured in the pressure side wake at $y / c x=0.10$ one axial chord length downstream of the cambered airfoil with big-sized roughness and $k s / c x=0.00258$. (a) $\mathrm{Tu}=1.1$ percent. (b) $\mathrm{Tu}=7.7$ percent.

longer times are required for a sufficient concentration of vorticity to be carried across the wake and to initiate shedding as the wake layer is diffused.

Figures 10(a) and 10(b) present PSD profiles measured downstream of an airfoil with uniform big-sized roughness $(k s / c x=0.00258)$ at inlet turbulence intensity levels of 1.1 percent and 7.7 percent, respectively. Note that the vortex shedding frequency presented in Figure 10(b) is much higher than that produced by the bar grid, as mentioned earlier. Thus, the different frequencies of the vortical events shed from airfoil and the bar grid indicate that separate structures are shed from the two components which are distinguishable from each other. For the airfoil with uniform bigsized roughness, the differences between vortex shedding frequencies under different inlet $\mathrm{Tu}$ values are negligible. This means that vortex shedding frequency is not sensitive to inlet turbulence intensity level for airfoils with surfaces with substantial amounts of roughness. The present data also show that vortex shedding frequencies are more recognizable in spectra measured in wakes downstream of smooth airfoils than rough airfoils. However, regardless of these variations, spectral peak results given in Figures 8, 9, and 10, in most cases, are significantly higher than energy levels of turbulent motions at neighboring frequencies.

Figure 11 shows the effects of surface roughness and inlet turbulent intensity level on nondimensional vortex shedding frequency. This nondimensional frequency is presented in the form of a Strouhal number $S$, which is given by

$$
S=\frac{f d}{u_{e, \infty}}
$$

Note that the present paper uses airfoil trailing edge thickness to determine the Strouhal number given in Figure 11 because it is well recognized that this is a key parameter in

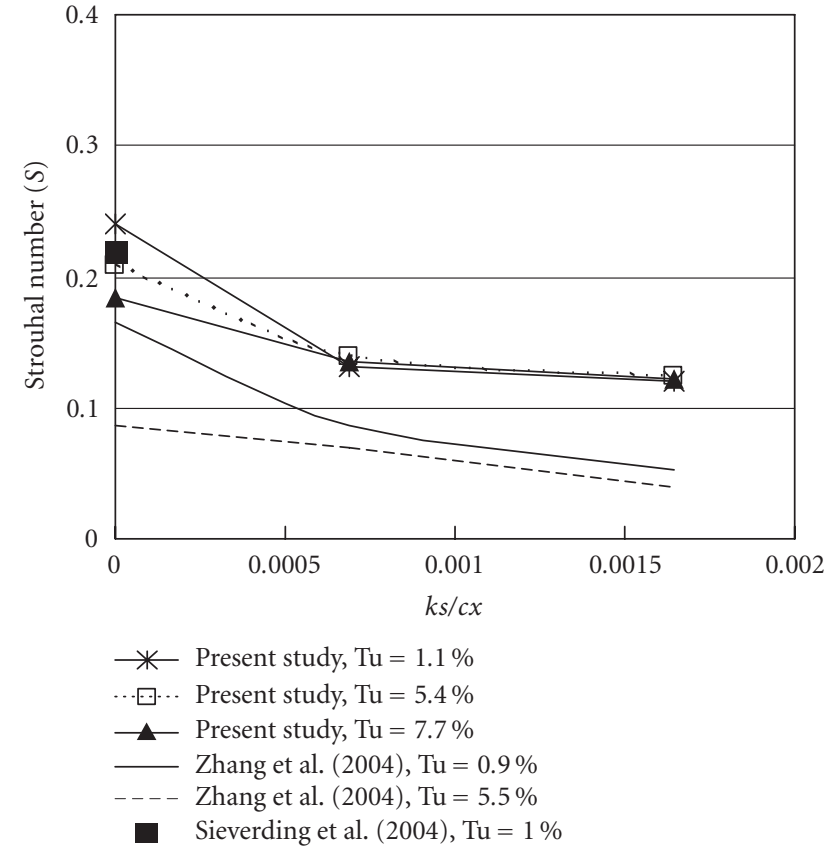

FIGURE 11: Vortex shedding frequency Strouhal numbers as dependent upon the normalized equivalent sand grain roughness size for different inlet turbulence intensity levels. Results are based upon power spectra density profiles measured in the pressure side wake at $y / c x=0.10$ one axial chord length downstream of the cambered airfoils.

regard to trailing edge vortex shedding. The dimensional magnitude of trailing edge thickness is proprietary and cannot be provided in the present paper. Data in Figure 11 show that the Strouhal number generally decreases as surface roughness size increases and is not sensitive to inlet 
turbulence intensity level, especially for airfoils with rough surfaces. Note that this insensitivity to inlet turbulence intensity level also provides evidence that vortical motions produced by the bar grid have negligible effect on the wake vortex shedding. Data by Zhang et al. [8] and Sieverding et al. [14] are also given in Figure 11. According to Sieverding et al. [14], a Strouhal number of around 0.2 is typical for a smooth surface airfoil with turbulent boundary layers on suction and pressure sides near the trailing edge.

\section{SUMMARY AND CONCLUSIONS}

Experimentally investigated are the effects of surface roughness and freestream turbulence levels on the wake characteristics of a cambered turbine airfoil. Three different freestream turbulence intensity levels (1.1 percent, 5.4 percent, and 7.7 percent) and four different surface roughness arrangements are employed, including (i) smooth, (ii) small-sized roughness with $k s / c x=0.00108$, (ii) big-sized roughness with $k s / c x=0.00258$, and (iv) variable roughness on the airfoil pressure side. Thus, new quantitative data are provided for experimental conditions and configurations not previously investigated.

When compared at the approximate same Mach number and equivalent sand grain roughness size, the cambered airfoil produces larger streamwise velocity deficits, higher normalized longitudinal turbulence intensity profiles, broader wakes compared to the symmetric airfoil. These differences are, in part, due to an enhanced flow diffusion zone near the suction surface trailing edge of the cambered airfoil (a type of behavior commonly observed on many different cambered airfoils). Normalized wake profiles of streamwise velocity and longitudinal turbulence intensity and nondimensional vortex shedding frequencies also have significant dependence on surface roughness, but are generally less sensitive to variations of freestream turbulence intensity.

In general, wake mean velocity deficits and longitudinal turbulence intensity levels increase at each $y / c x$ location within the wake downstream of the cambered airfoil as $k s / c x$ increases. These alterations with increased surface roughness size are because of different boundary layer development with increasing roughness, augmentations of mixing and turbulent transport in the thicker boundary layers, and increased turbulent diffusion within the wake. The variable roughness placed on the airfoil pressure side increases wake velocity deficits only by small amounts compared to a smooth airfoil. This provides evidence that roughness on the airfoil pressure side has relatively smaller effects (than roughness placed on the suction side) on the mean velocity profile within the wake. Compared with wake profiles from a symmetric airfoil, asymmetry is present in all the wake profiles measured downstream of the cambered airfoil. Suction side wakes (at negative $y / c x$ ) are then thicker than the pressure side wakes (at positive $y / c x$ ) due to different boundary layer development on the suction and pressure sides, and due to enhanced flow diffusion zones near the trailing edges of the suction sides of the cambered airfoils.
Power spectral density profiles of the fluctuating longitudinal component of velocity in the wake are given to provide information on coherent structures in the form of von Kármán vortices. PSD profiles measured within the pressure side wake at $y / c x=0.10$ show that surface roughness generally decreases the nondimensional frequency of vortex shedding due to thickened boundary layers, earlier trailing edge separations, and larger diffusion within and from the wake. These nondimensional vortex shedding frequencies are generally not as sensitive to inlet turbulence intensity level, especially for airfoils with surfaces with significant roughness.

\section{NOMENCLATURE}

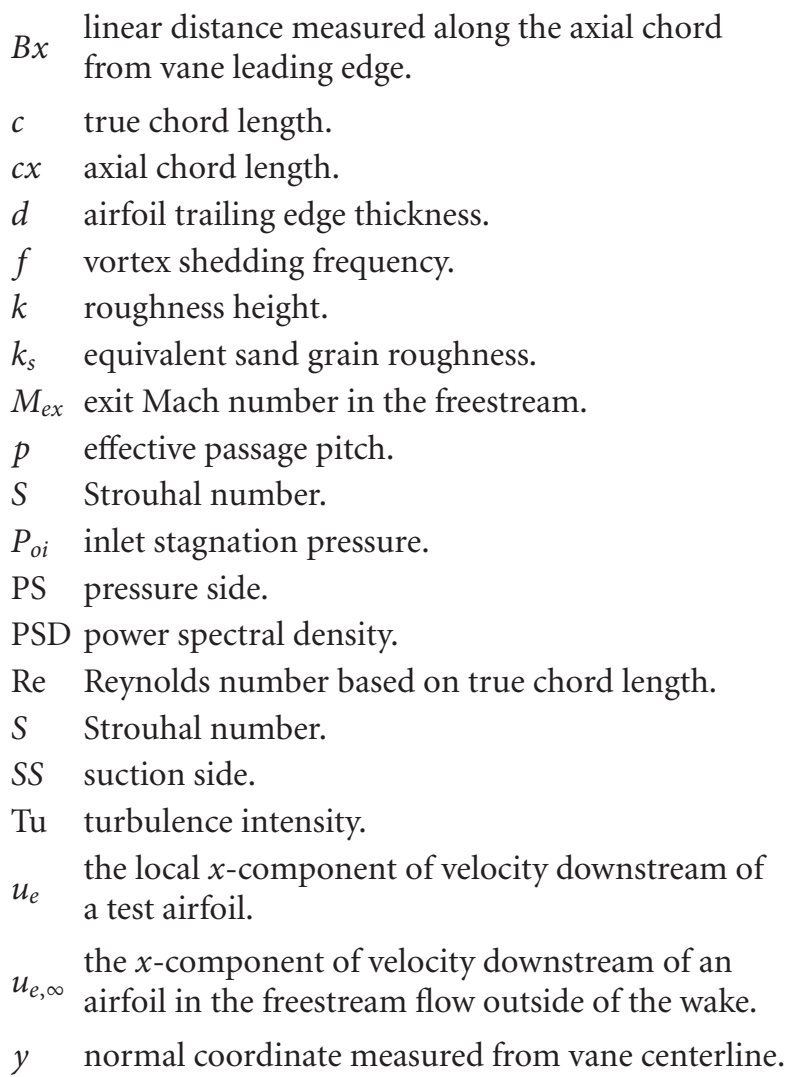

\section{SUBSCRIPTS}

e exit.

$\infty$ freestream.

\section{ACKNOWLEDGMENTS}

The research reported in this paper was sponsored by the National Science Foundation (NSF) Grant number CTS0086011. Dr. Stefan Thynell and Dr. Richard Smith were the NSF program monitors. The authors also acknowledge Mr. Mike Blair of Pratt \& Whitney Corporation, Dr. HeeKoo Moon of Solar Turbines Incoration, Mr. Edward North and Mr. Ihor Diakunchak of Siemens-Westinghouse Corpo- 
ration, and Dr. Richardo Trindade and Dr. Sri Sreekanth of Pratt \& Whitney-Canada Corporation for guidance and suggestions on this research effort, and for providing roughened turbine blade hardware from engines for analysis and comparison.

\section{REFERENCES}

[1] J. H. Gerrard, "The mechanics of the formation region of vortices behind bluff bodies," Journal of Fluid Mechanics Digital Archive, vol. 25, no. 2, pp. 401-413, 1966.

[2] A. E. Perry, M. S. Chong, and T. T. Lim, "The vortex-shedding process behind two-dimensional bluff bodies," Journal of Fluid Mechanics, vol. 116, pp. 77-90, 1982.

[3] B. Cantwell and D. Coles, "Experimental study of entrainment and transport in the turbulent near wake of a circular cylinder," Journal of Fluid Mechanics, vol. 136, pp. 321-374, 1983.

[4] H. Makita and K. Sassa, "Visualization and measurement of the wakes of two dimensional bodies in the strong turbulence," in Turbulence Measurements and Flow Modeling, C. J. Chen, L. D. Chen, and F. M. Holly, Eds., pp. 1-137, Hemisphere, Washington, DC, USA, 1986.

[5] J. M. Cimbala and M. V. Krein, "Effect of freestream conditions on the far wake of a circular cylinder," AIAA journal, vol. 28, no. 8, pp. 1369-1373, 1990.

[6] Y. Zhou and R. A. Antonia, "Effect of initial conditions on vortices in a turbulent near wake," AIAA journal, vol. 32, no. 6, pp. 1207-1213, 1994.

[7] L. Ong and J. Wallace, "Velocity field of the turbulent very near wake of a circular cylinder," Experiments in Fluids, vol. 20, no. 6, pp. 441-453, 1996.

[8] Q. Zhang, S. W. Lee, and P. M. Ligrani, "Effects of surface roughness and freestream turbulence on the wake turbulence structure of a symmetric airfoil," Physics of Fluids, vol. 16, no. 6, pp. 2044-2053, 2004.

[9] G. S. Cambell, "Turbulence in the wake of a thin airfoil at low speeds," Technical memorandum 1427, National Advisory Committee for Aeronautics (NACA), Washington, DC, USA, 1957.

[10] C. Hah and B. Lakshminarayana, "Measurement and prediction of mean velocity and turbulence structure in the near wake of an airfoil," Journal of Fluid Mechanics, vol. 115, pp. 251-282, 1982.

[11] L. S. Han and W. R. Cox, "Visual study of turbine blade pressure-side boundary layers," Journal of Engineering for Power: Transactions of the ASME, vol. 105, no. 1, pp. 47-52, 1983.

[12] C. H. Sieverding and H. Heinemann, "Influence of boundary layer state on vortex shedding from flat plates and turbine cascades," in American Society of Mechanical Engineers (Paper), Toronto. Ontario, Canada, June 1989, ASME paper GT296.

[13] C. H. Sieverding, G. Cicatelli, J. M. Desse, M. Meinke, and P. Zunino, "Experimental and numerical investigation of time varying wakes behind turbine blades," in Results of the Industrial and Material Technology Aeronautics Research Preject AER2-CT92-0048, 1992-1996, vol. 67 of Notes on Numerical Fluid Mechanics, Geronimo GmbH, Rosenheim, Germany, 1999.

[14] C. H. Sieverding, D. Ottolia, C. Bagnera, A. Comadoro, J.-F. Brouckaert, and J.-M. Desse, "Unsteady turbine blade wake characteristics," Journal of Turbomachinery: Transactions of the ASME, vol. 126, no. 4, pp. 551-559, 2004.
[15] Q. Zhang and P. M. Ligrani, "Mach number/surface roughness effects on symmetric transonic turbine airfoil aerodynamic losses," AIAA Journal of Propulsion and Power, vol. 20, no. 6, pp. 1117-1125, 2004.

[16] D. J. Jackson, K. L. Lee, P. M. Ligrani, and P. D. Johnson, “Transonic aerodynamic losses due to turbine airfoil, suction surface film cooling," Journal of Turbomachinery: Transactions of the ASME, vol. 122, no. 2, pp. 317-326, 2000.

[17] T. Furukawa and P. M. Ligrani, "Transonic film cooling effectiveness from shaped holes on a simulated turbine airfoil," AIAA Journal of Thermophysics and Heat Transfer, vol. 16, no. 2, pp. 228-237, 2002.

[18] J. A. van Rij, B. J. Belnap, and P. M. Ligrani, "Analysis and experiments on three-dimensional, irregular surface roughness," Journal of Fluids Engineering: Transactions of the ASME, vol. 124, no. 3, pp. 671-677, 2002.

[19] K. Bammert and H. Sandstede, "Influences of manufacturing tolerances and surface roughness of blades on the performance of turbines," American Society of Mechanical Engineers (Paper), no. 75-GT-35, pp. 1-8, 1975.

[20] K. Bammert and H. Sandstede, "Measurements on the boundry layer development along a turbine blade with rough surfaces," Journal of Engineering for Power: Transactions of the ASME, vol. 102, no. 4, pp. 978-983, 1980.

[21] R. J. Kind, P. J. Serjak, and M. W. P. Abbott, "Measurements and prediction of the effects of surface roughness on profile losses and deviation in a turbine cascade," in Proceedings of the International Gas Turbine and Aeroengine Congress \& Exhibition, pp. 1-10, Burmingham, UK, June 1996, ASME paper 95-GT-203.

[22] D. G. Bogard, D. L. Schmidt, and M. Tabbita, "Characterization and laboratory simulation of turbine airfoil surface roughness and associated heat transfer," Journal of Turbomachinery: Transactions of the ASME, vol. 120, no. 2, pp. 337-342, 1998.

[23] N. Abuaf, R. S. Bunker, and C. P. Lee, "Effects of surface roughness on heat transfer and aerodynamic performance of turbine airfoils," Journal of Turbomachinery: Transactions of the ASME, vol. 120, no. 3, pp. 522-529, 1998.

[24] R. Leipold, M. Boese, and L. Fottner, "The influence of technical surface roughness caused by precision forging on the flow around a highly loaded compressor cascade," Journal of Turbomachinery: Transactions of the ASME, vol. 122, no. 3, pp. 416425, 2000.

[25] F. Hummel, M. Lötzerich, P. Cardamone, and L. Fottner, "Surface roughness effects on turbine blade aerodynamics," Journal of Turbomachinery: Transactions of the ASME, vol. 127, no. 3, pp. 453-461, 2005.

[26] R. J. Boyle and R. G. Senyitko, "Measurements and predictions of surface roughness effects on turbine vane aerodynamics," in Proceedings of the American Society of Mechanical Engineers, International Gas Turbine Institute, Turbo Expo (IGTI '03), vol. 6, pp. 291-303, Atlanta, Ga, USA, June 2003, ASME paper GT2003-38580. 

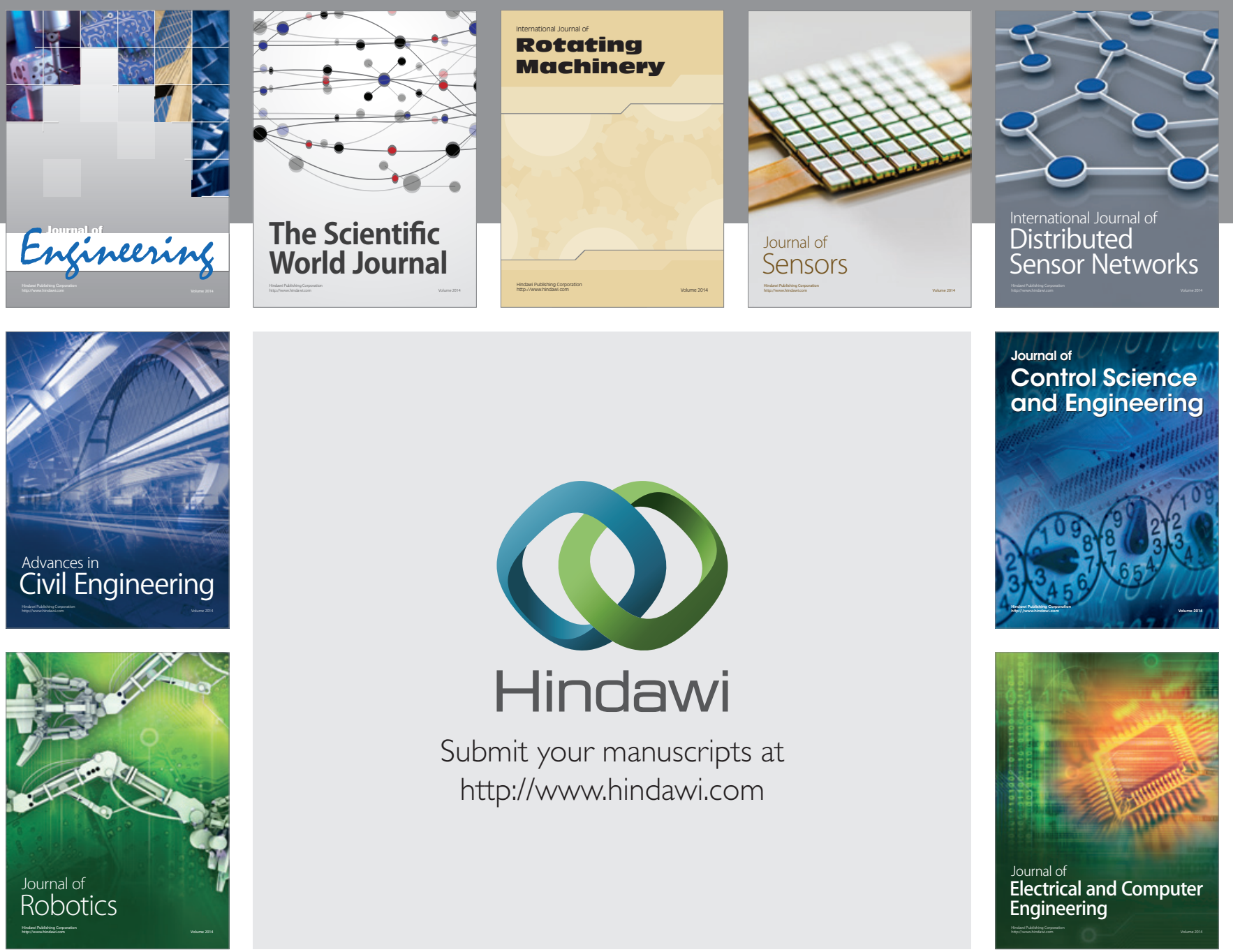

Submit your manuscripts at

http://www.hindawi.com
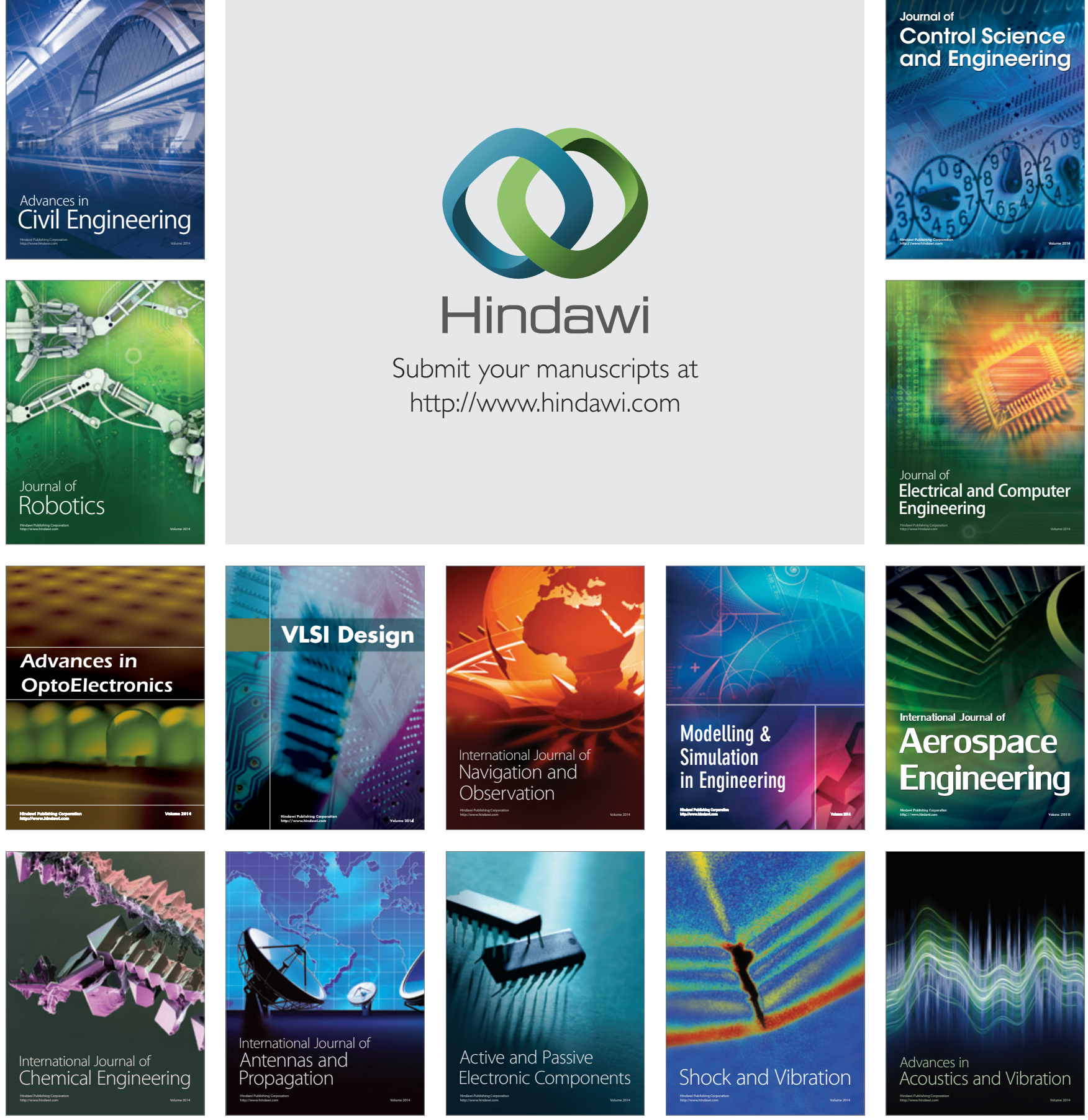